\title{
LONG-TERM SUBSIDENCE OF BEACH NOURISHMENT AND DUNE RESTORATION IN CAMINADA HEADLANDS, COASTAL LOUISIANA
}

Navid H. Jafari, Louisiana State University, njafari@lsu.edu

Brian D. Harris, Louisiana State University, bhar96@Isu.edu

Timothy D. Stark, University of Illinois, tstark@illinois.edu

\begin{abstract}
INTRODUCTION
Coastal barrier islands are the first line of defense for protecting wetlands, inland bays, and mainland regions from direct effects of wind, waves, and storms. Rosati (2006) indicate that 20 to $40 \%$ of the total sand volume can be sequestered and lost from the sandy barrier island through consolidation. As a result, predicting long-term subsurface sediment consolidation is integral to determining the ability of barrier islands to provide coastal protection and resilience to future hazards, such as relative sea level rise, sediment erosion, and hurricanes. This study uses the Caminada Headlands geotechnical investigations and monitoring data to determine empirical correlations for deltaic sediment compressibility and develop a validated and calibrated consolidation and subsidence numerical model for future barrier island restoration projects. With this calibrated model, differential settlements associated with sand fill placement can be estimated to design placement elevations to maintain post-construction topography for ecological habitat and restoration requirements and can be used for future beach restoration projects along barrier island shorelines.
\end{abstract}

GEOLOGICAL PROPERTIES AND CORRELATIONS Five geotechnical subsurface investigations at the Caminada Headlands resulted in 51 consolidation tests to determine the physical index properties and compressibility properties of the underlying foundation sediments prior to sand fill placement. The subsurface profile at the boring locations generally consists of fine sand with shells and organics at the surface, which overlies interbedded layers of fine sand and silty clay, clay with the presence of silty clay, and clay with depth. Beach deposits are present approximately $7.6 \mathrm{~m}$ to $8.5 \mathrm{~m}$ below the ground surface, with back-bay marsh deposits underlying the beach sand. Sand interbeds were encountered within the back-bay marsh deposits with some regularity between depths of 14 to $18.3 \mathrm{~m}$ and 25.3 to $29.6 \mathrm{~m}$. From the 1-D consolidation tests, estimated compression indices (Cc) were used to develop correlations to physical index properties, such as natural moisture content ( $w \%)$, to facilitate estimating compressibility properties along the entire beach crosssection for the numerical modeling. Fig. 1 shows an example of the correlation developed for $\mathrm{Cc}$ and $\mathrm{w} \%$ at Caminada Headlands, where the dashed lines represent historical correlations. The disagreement between correlations illustrates the importance of characterizing soil properties based on regional geology.

\section{NUMERICAL MODELING}

To determine the applied stresses across the beach, the topographic surveys were input into the finite element stress-deformation analysis software RS2. The boundary conditions for the finite element mesh include rollers at the Left- and Right-Hand Sides of the model and pins at the bottom of the model. The initial effective stress was estimated from body (gravity) forces, and the beach fill was added in one time step as a new soil layer in RS2. The unit weight of the beach fill was estimated to be $18.2 \mathrm{kN} / \mathrm{m}^{3}$ based on particle size gradation $\left(\mathrm{Cu}=4.06, \mathrm{Cc}_{\mathrm{C}}=1.95\right)$ of the Ship Shoal sand.

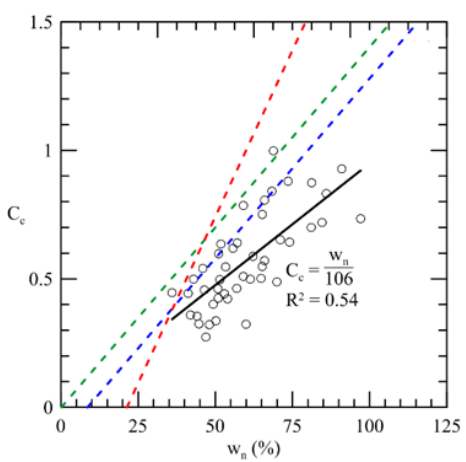

Fig. 1 Compressibility correlation at Caminada Headlands

The software Settle3D, a 3-dimensional program for the analysis of vertical consolidation and settlement under surface loads, was use to compare observed settlement from in-situ measurement and predicted model results. Terzaghi's 1-D consolidation theory was implemented in Settle3D, and the compressibility parameters for the clay layers were estimated from Fig. 1. The site was instrument with three surface settlement plates and 13 subsurface anchors to monitor the consolidation of specific clay layers in the foundation. Fig. 2 shows an example of the calibrated model.

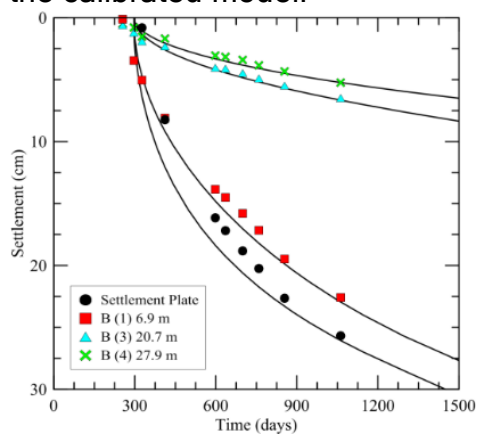

Fig. 2 Comparison of observed and modeled settlement CONCLUSIONS

Long-term simulations performed using a calibrated consolidation model of the Caminada Headlands shows that over $50 \mathrm{~cm}$ of settlement will occur during a 50 year project service life. This information is critical to understand the efficacy of beach and dune restoration projects especially with the possibility of future relative sea level rise in coastal Louisiana.

\section{REFERENCES}

Rosati (2006). "Restoration of Barrier Islands Overlying

Poorly-Consolidated Sediments, South-Central

Louisiana." Gulf Coast Association of Geological Societies Transactions, 56, 727-40. 